\title{
Preface
}

\section{1th International Workshop on Technical and Scientific Aspects of MST Radar (MST11)}

There has been a significant progress in the technical and scientific aspects of Mesosphere - Stratosphere-Troposphere (MST) radars to study lower, middle and upper atmosphere and having applications in operational meteorology. To discuss the recent advances made and also to plan the future research activities, the Eleventh International workshop on Technical and Scientific aspects of MST Radar MST 11 was held at National Atmospheric Research Laboratory (NARL), Gadanki, India, during 11-15 December 2006.

Globally important contributions are being continuously made to the advances in technical aspects of MST Radar with state-of-the-art technology, devices and processing techniques. Significant scientificcontributions are being made to the MST related science involving contemporary issues regarding the scientific and operational applications of MST/ ST Radars and wind profilers.

The workshop comprised of six main sessions encompassing the major topics of research and the scientific and operational applications:

1. Radar scattering processes in the atmosphere

2. Scattering from ionospheric irregularities

3. Instrumentation, technical and signal processing

4. Meteorology with atmospheric radars

5. Mean winds, waves and tides in the MST region (including CAWSES)

The topics relevant to CAWSES (Climate And Weather of the Sun-Earth System), an international program of SCOSTEP, were also among the important themes of the workshop.

About 300 participants from different parts of the world attended the workshop. Participation of a large number of research scholars and young scientists was a salient feature of MST 11. The workshop was sponsored by the National Atmospheric Research Laboratory (NARL), Department of Science and Technology, Government of India (DST), the Research Institute for Sustainable Humanosphere (RISH),
Kyoto University, Japan, SCOSTEP (specifically through CAWSES), URSI (in particular commissions F and G), Mardoc Inc. and Metek.

The workshop was inaugurated by A. P. J. Abdual Kalam, the President of India. In his inaugural address, Abdul Kalam emphasized the importance of the the MST Radar set up in Gadanki, India, that has become an important research tool for the Indian and international scientific community. $\mathrm{He}$ also expressed the need to study the dynamical changes occurring in the troposphere, the stratosphere and the mesosphere with reference to climate change. The presidential address was delivered by G. Madhavan Nair, Chairman, Indian Space Research Organisation (ISRO).

The Extended Abstracts of this workshop were published as Proceedings having 791 pages. The authors of some of the papers presented in MST 11 accepted the opportunity offered for formal publication and these papers endured the standard refereeing procedure of Annales Geophysicae. Thus, the present special issue represents a partial overview on the technical and scientific development of radar research of the Troposphere, Stratosphere, Mesosphere and Ionosphere.

Since this field of research is continuously developing, the 12th workshop on Technical and Scientific aspects of MST Radar is held in Ontario, Canada in May 2009.

We thank U. P. Hoppe, the Topical Editor of Annales Geophysicae for providing an opportunity for the MST radar community to publish these papers in this special issue. We thank the referees for their support and appreciate the helpful assistance of the Editorial Office of Annales Geophysicae. We gratefully acknowledge the hospitality of National Atmospheric Research Laboratory (NARL) and Indian Space Research Organization (ISRO) and their contribution to the organisation and conduct of the workshop.

\section{Narayana Rao, Jürgen Röttger, Toshitaka Tsuda, and S. Gurubaran \\ Guest editors}

